\title{
Facilitating participatory multilevel decision-making by using interactive mental maps
}

\author{
Constanze Pfeiffer ${ }^{1}$, Stephanie Glaser ${ }^{2}$, Jayshree Vencatesan³ ${ }^{3}$ Elke Schliermann-Kraus², \\ Axel Drescher ${ }^{2}$, Rüdiger Glaser ${ }^{2}$ \\ ${ }^{1}$ Department of Public Health and Epidemiology, Swiss Tropical Institute, P.O. Box, CH-4002 Basel, \\ Switzerland; ${ }^{2}$ Department of Physical Geography, University of Freiburg, Werthmannstraße 4, D-79085 \\ Freiburg, Germany; ${ }^{3}$ Care Earth, 21st Street Thillaiganga Nagar, Chennai 600 061, India
}

\begin{abstract}
Participation of citizens in political, economic or social decisions is increasingly recognized as a precondition to foster sustainable development processes. Since spatial information is often important during planning and decisionmaking, participatory mapping gains in popularity. However, little attention has been paid to the fact that information must be presented in a useful way to reach city planners and policy makers. Above all, the importance of visualisation tools to support collaboration, analytical reasoning, problem solving and decision-making in analysing and planning processes has been underestimated. In this paper, we describe how an interactive mental map tool has been developed in a highly interdisciplinary disaster management project in Chennai, India. We moved from a hand drawn mental maps approach to an interactive mental map tool. This was achieved by merging socio-economic and geospatial data on infrastructure, local perceptions, coping and adaptation strategies with remote sensing data and modern technology of map making. This newly developed interactive mapping tool allowed for insights into different locally-constructed realities and facilitated the communication of results to the wider public and respective policy makers. It proved to be useful in visualising information and promoting participatory decision-making processes. We argue that the tool bears potential also for health research projects. The interactive mental map can be used to spatially and temporally assess key health themes such as availability of, and accessibility to, existing health care services, breeding sites of disease vectors, collection and storage of water, waste disposal, location of public toilets or defecation sites.
\end{abstract}

Keywords: participatory mapping, risk assessment, decision-making, visualisation, health research, India.

\section{Introduction}

The demand for participation of citizens in political, economic or social decisions is growing, reflecting the need to integrate the ideas and experiences of those affected by decisions (Mukherjee, 1993; Wright and Nelson, 1994; Chambers, 1997). Considering the voices of citizens has been proven to be crucial for the sustainability of interventions as well as the creation of ownership and acceptance

Corresponding author:

Rüdiger Glaser

Department of Physical Geography

University of Freiburg

Werthmannstraße 4, 79085 Freiburg, Germany

Tel. +49 761203 3527; Fax +49 7612033596

E-mail: ruediger.glaser@geographie.uni-freiburg.de among different stakeholders. Therefore, collaboration with, and involvement of, citizens is becoming more and more important for policy makers worldwide. Meanwhile, different tools have been and still are developed that not only allow for learning from community members themselves, but provide ways in which they can actively identify and express their concerns, needs and opinions to policy makers. Since spatial information is often crucial during planning and decision-making, participatory mapping has gained popularity. It is mainly used to facilitate public involvement and to connect community members with policy makers (Abbot et al., 1998; Harris and Weiner, 1998; Vajjhala, 2006; Dunn, 2007).

The idea of using maps to illuminate problems is not a new one. In geography, Kevin Lynch, author 
of "The Image of the City" (Lynch, 1960), is deemed to be a protagonist regarding the application of visual techniques while analysing the spatial behaviour of the people of Boston, Los Angeles and Jersey in the United States of America. Since that time, manifold examples and further developments, especially in behavioural geography and risk analysis, have been using maps for information presentation. Maps are understandable with little verbal aid, show the intended information immediately and reveal the spatial context.

When we use the term "participatory maps", we refer to the concept of mental maps. Mental maps are defined as maps of individuals or groups that provide information about local perceptions of space and how actors structure the space that surrounds them (Downs and Stea, 1982). Mental maps allow for uncovering the constructed realities of people and their individual spatial behaviour - often seen as a contradiction to the logical and economic principles of the ideal of a "homo oeconomicus", which is frequently used in models. While creating mental maps, participants visualise their so-called tacit knowledge that they are otherwise often not aware of. Building up on Berger and Luckmann's concept of social constructivism, we argue that knowledge is derived from, and maintained by, social interactions. Social constructions are influenced by the culture and the context in which they take place. People interact with the understanding that their respective perceptions of reality are related, and as they act their common knowledge of reality becomes reinforced (Berger and Luckmann, 1966; Treibel, 2000).

Mental maps give insights into locally constructed positive or negative connotations of space, important landmarks or the perceived size of the covered geographical areas. In the late 1980s, participatory mental maps started to be used in order to elicit indigenous knowledge. However, by then interaction between communities and policy makers was scarce. In the 1990s, this changed with the introduction of geographical information systems (GIS) as well as open access to data via the Internet.
Participatory GIS (PGIS), which is a combination of participatory data collection methods and GIS, developed (Abbot et al., 1998; Barndt, 1998; MacEachren, 2000; Rambaldi et al., 2004; Dunn, 2007). Although PGIS has become popular, little attention has yet been paid to the fact that information must be prepared and presented in a useful, yet appealing way to reach city planners and policy makers alike. PGIS should be structured, digitally stored and managed in a sustainable manner. The importance of visualisation tools to support collaboration, analytical reasoning, problem solving and decision-making in analysing and planning processes has been underestimated (Tomaszewski et al., 2007). In order to communicate the information gained during map-making to the wider public and responsible authorities on local, regional, national or international levels, we developed and applied a flash-based visualisation technology. We argue that interactive modules open new oportunities to stimulate the communication processes and/or to visualise single steps of the development.

\section{Materials and methods}

\section{Study area}

In the south Indian megacity of Chennai, disastrous tropical monsoon linked with excessive precipitation frequently leads to wide-flat floods in the coastal plains. Due to rapid urbanisation, the population in urban and periurban areas is more and more affected by these events. Besides the marginalised population living in disfavoured areas, also the wealthier population that settles in flood prone areas is increasingly affected (Nestle et al., 2005; Glaser et al., 2006). The situation is characterised by complex interrelations of anthropogenic and ecological factors. Interdisciplinary assessments are needed to explain the various causes of floods. An international team of social and natural scientists aimed at assessing these interrelated factors within a research project "Risk assessment of extreme precipitation in the coastal areas of Chennai and 
Pondicherry as element of catastrophe prevention". The project analysed environmental aspects of risk exposure as well as socio-economic aspects of risk perceptions and response strategies.

\section{Theoretical framework}

The risk assessment was theoretically embedded in a risk and vulnerability framework. Risk and vulnerability concepts have a long history in disaster research. In the past, researchers acknowledged the fact that it is not sufficient to look at environmental exposure and stressors only, since this leaves out information about different human response strategies as well as impacts (Bohle, 2001; GTZ, 2004). Turner et al. (2003) developed an expanded vulnerability framework, which sets the focus on the multifaceted synergies and linkages between human and environmental aspects. The framework takes into consideration that in case of a disaster, such as floods, vulnerability is not determined by exposure to risk only, but also by the sensitivity and resilience as well as coping and adaptation strategies of those affected. Building on Turner et al. (2003), we argue that perceptions of risk, sensitivity and resilience are constructed and differ between people and regions. As Stallings (1995) points out, some events or threats in one region are collectively defined as public concerns, while others are not. Capturing these apparent "realities" helps to better understand local coping and adaptation strategies as well as policy processes.

\section{Multi-method approach}

Following the theoretical framework outlined above, we used an integrative multi-method approach combining socio-economic with physiogeographic, hydrological and meteorological data. The study took place in three different areas in southern Chennai, located in the neighbourhood of the socalled Pallikaranai Marsh. In order to cover a range of realities, a low-income encroachment area, a lowincome rehabilitated settlement as well as a middle- income settlement were selected as research sites.

Physio-geographic, hydrological and meteorological realities in risk areas were assessed using remote sensing (RS) data and GIS. RS (Corona images, Landsat MSS, TM and ETM, Aster and Quickbird imagery) in differing resolutions, spectral and temporal ranges covering the period from the 1960s up to 2006 were analysed. A high resolution Quickbird satellite image from October 2006 was of particular use to obtain recent data of the study area. This image was shared with the Indian project partners, who added their on-site knowledge about floods of the past few years and integrated it into the vectorised data created from the various satellite images.

Moreover, the RS images were applied to vectorise the extent of the main waterbody of the marshland in a multi-temporal mode. Out of this sequence it was possible to derive the relation between amount of rainfall and extent of the water body based on a transfer function. Next, the RS data were used to get information about land use and land cover change, distinguishing between the main classes of settled areas and infrastructure, open land and agricultural areas, water body and marshland. The classification was verified by comparing a range of historical data, topographic maps and photos. Detailed transect walks conducted during field stays in 2006 and 2007 allowed for the necessary ground truthing.

In addition, affected marginalised poor segments of the population and middle class groups were interviewed individually and in groups in order to analyse local perceptions of floods and dominant management strategies. With the help of a local community worker, members of the research areas could be mobilised to participate in participatory mapping activities. Each research site was represented by one group (Fig. 1).

The mapping was started by identifying community boundaries and infrastructure. In order to learn about the historic dimensions of floods, time-lines were selected. In doing so, floods of the last 20 years and their extents were demarcated. Based on this information, discussion took place about response strategies used before, during and after floods. 


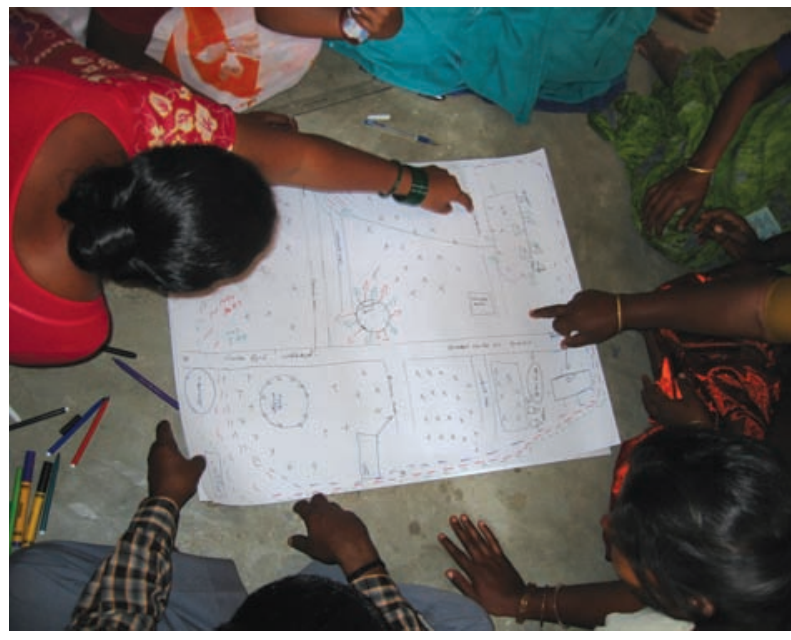

Fig. 1. Participatory mapping.

\section{Results}

\section{Satellite images and maps}

The analysis of the multi-temporal data set, historical as well as recent land classification clearly indicated a pronounced alteration of settlements which began mushrooming into the marshland when the information technology (IT) boom started.

The RS data gave insights into the rapid and fundamental land use and land cover change around the marshland. They revealed the shrinking of the water body and the retreat of the agricultural land on the one hand, as well as the enlargement of the settlement area especially into critical areas of the marshland on the other hand (Fig. 2).

The intensity of floods is based on the precondition of the respective area. For Chennai and the marshland, floods have different intensities due to the expansion of the water bodies in the marshland. Regularly flooded neighbourhoods were identified in high resolution Quickbird scenes (Fig. 3). The larger the water bodies are at the end of the dry season, the higher is the risk of a flood. A regression function was derived as a transfer model between the amount of rainfall and the extent of a water body. The relation indicates a high correlation between the water body sizes at the end of dry sea- sons and the precipitation amounts of the year before.

\section{Flash-based visualisation of mental maps}

Visualisation and especially geo-visualisation is not limited to scientific purposes. Rapid advances in web-cartography and GIS as well as in IT and communication technology have created a potential for dynamic and interactive visualisation methods, which are increasingly used by decision makers and planners. Meanwhile, a wide set of tools has been developed that allows for visual exploration, analysis, synthesis and especially processes to interact, combine and exchange complex data sets and information. We used Adobe Flash ${ }^{\circledR}$ (Adobe Systems Incorporated, San Jose, USA), a multimedia authoring and application software for developing interactive content. In the case of Adobe Flash ${ }^{\circledR}$-based multimedia mental maps, spatial data, for instance, remote satellite imageries or topographic maps can be combined with other geodata such as socio-economic or health information. One of the main concepts of visualisation is to give users the possibility to explore knowledge by interaction. In this way, it can be applied for presenting and communicating different interests between stakeholders. However, the full potential of multimedia mental maps is not yet used in practice.

From hand drawn mental maps to an interactive mental map tool

Developing and designing an Adobe Flash ${ }^{\circledR}$-based interactive mental map tool for supporting decisionmaking required several implementation steps. We transferred the hand drawn mental maps in a digital version of the maps for more useful and precise analysis (Fig. 4).

Following cartographic rules, a comprehensive and generally understandable legend had to be defined. Linguistic and hand drawn information had to be translated into icons, symbols, or to be transferred in a more digital way into lines, poly- 

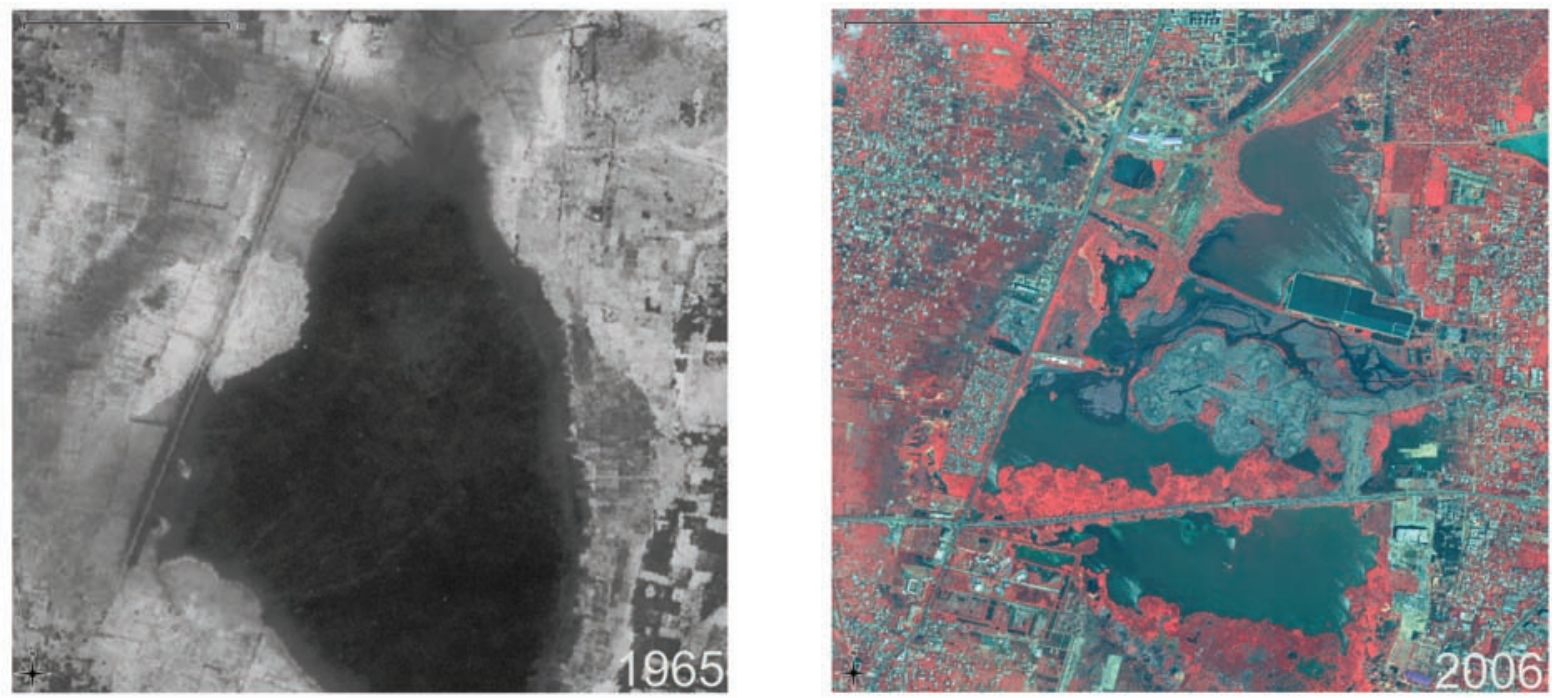

Fig. 2. Land use and land cover change around the marshland 1965 (Corona) to 2006 (Quickbird - bandcombination 421).
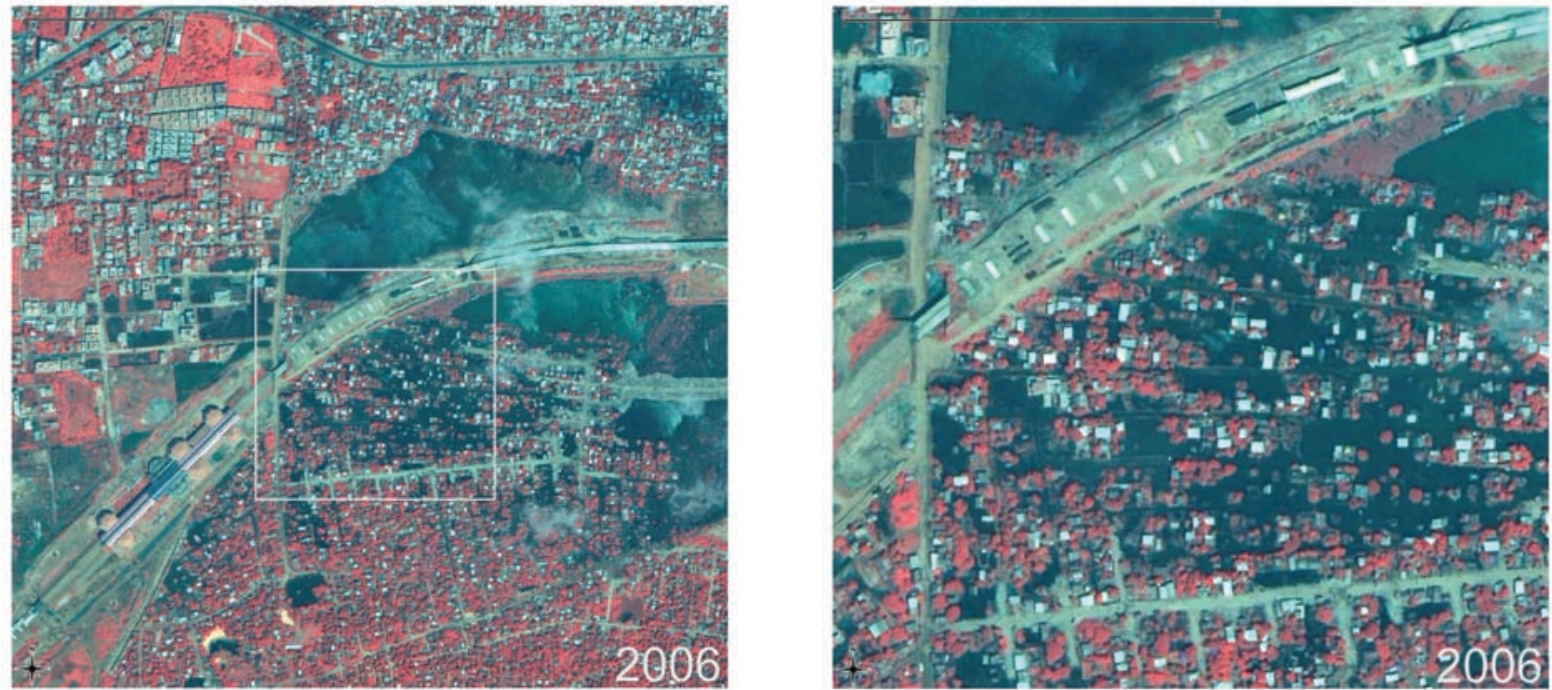

Fig. 3. Flooded neighbourhood in 2006 (Quickbird - bandcombination 421).

gons and points. This important step did raise fundamental questions concerning cartographic symbolisation, geographic layer definition, generalisation and simplification, layout and design of maps.

The digital mental maps proved to be a very accurate transformation of the original information into digitally readable elements. In order to compare the mental maps with the topographic reality, we used a Quickbird satellite image as an overlay. The combination with georeferenced highly resolved satellite imagery showed a very high accordance. The ground truthing therefore can also be seen as an additional verification. 


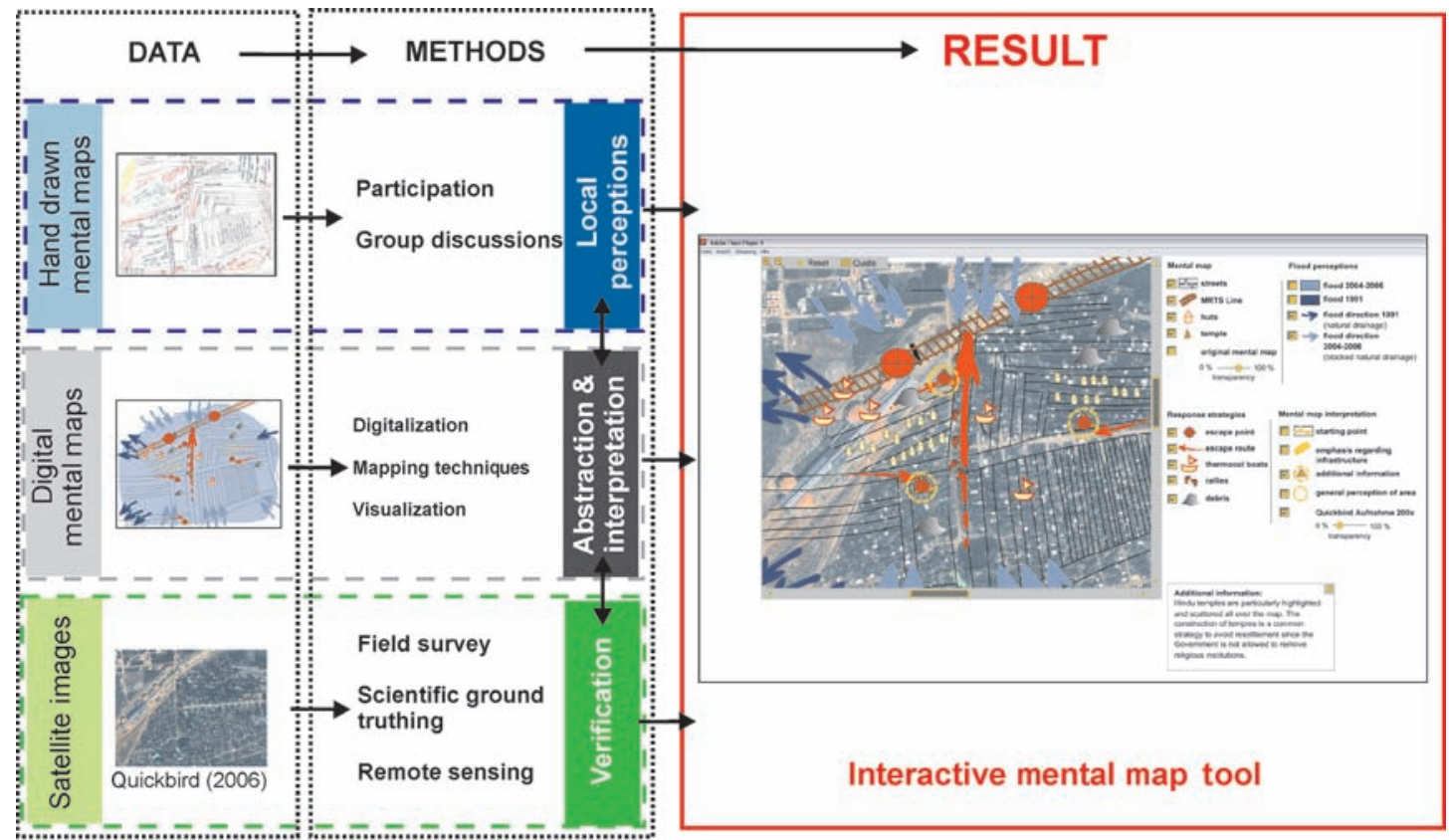

Fig. 4. Developing an interactive mental map tool.

\section{Advantages of an interactive mental map tool}

If the translation of raw data such as hand drawn mental maps, digital mental maps and satellite images is successful, the resulting interactive mapping tool merges interdisciplinary data on infrastructure, local perceptions as well as coping and adaptation strategies with RS data and modern technology of map making. By doing this, a multifaceted presentation of the situation can be obtained (Fig. 5).

Therefore, maps can be considered as an instrument that initiates reflection processes among users, which in turn helps to efficiently and effectively communicate research results for improving and supporting planning and decision-making.

\section{Discussion}

\section{Adobe Flash ${ }^{\circledR}$-based mapping tool}

The integrated programming language Action Script enables wide scope for designing interactive dynamic maps. The developed animations can be presented via the Internet or as an offline version. The Flash plugin is available on $98 \%$ of users' computer desktop. Additionally, map files (.SWF files) are up to about $25 \%$ smaller than equivalent Javabased files. This contributes to a faster user experience.

\section{Supporting decision-making in Chennai}

Using visualisation for decision-making is an auspicious procedure to combine both local views by applying a bottom-up approach as well as institutional perspectives following a top-down approach. Knowledge exchange between heterogeneous groups is often a critical point bogged down by factors that are often not readily recognisable. Visualisation of data is extremely helpful in order to illustrate information and attitudes of stakeholders on various levels to support mutual solution-finding processes. Further, visualisation of data becomes irreplaceable in situations where the participating group is illiterate or marginalised by social pressure.

Our tool was presented and used during two pol- 


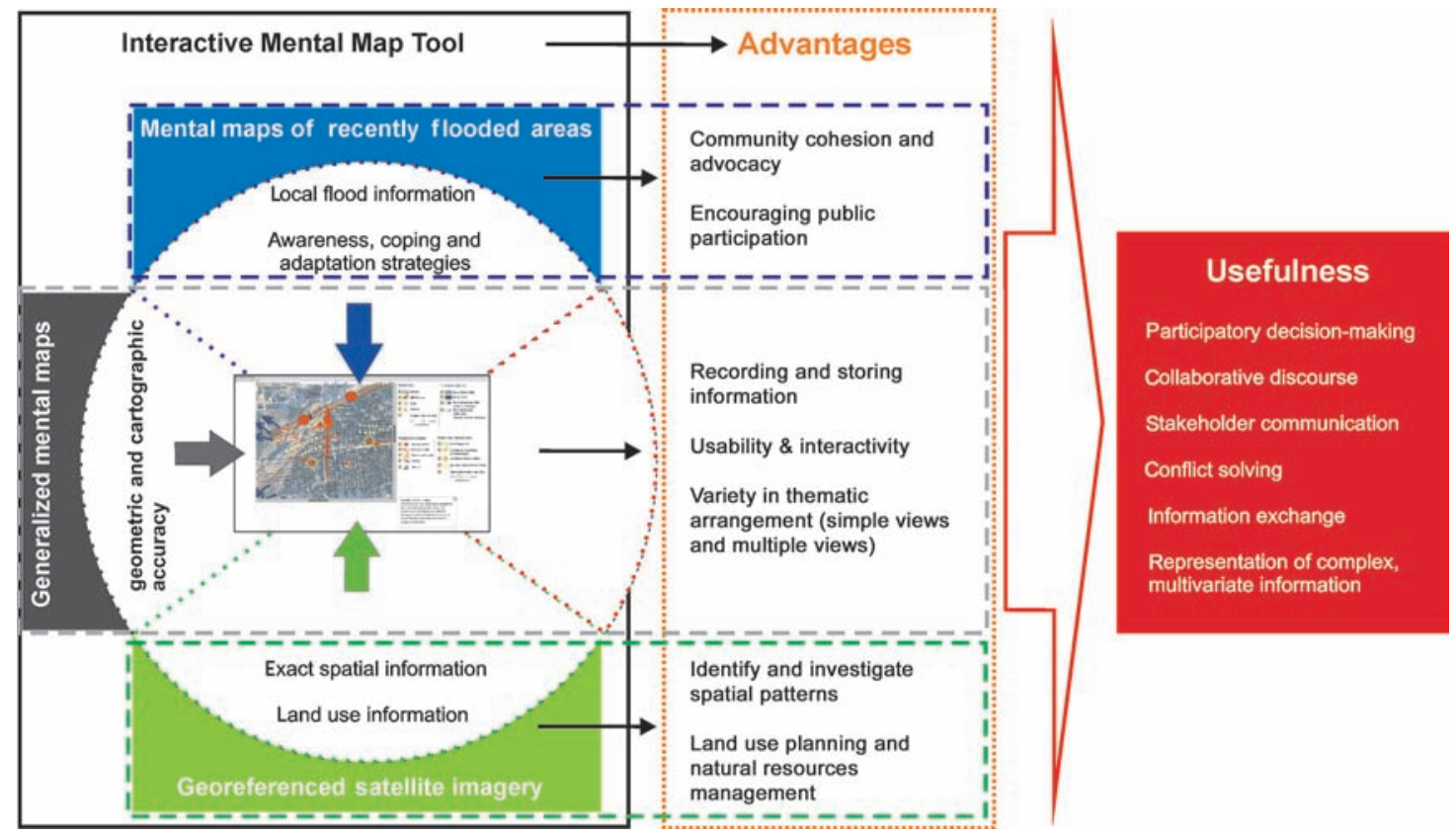

Fig. 5. Advantages and usefulness of an interactive mental map tool.

icy workshops. In August 2007, the first one took place in Chennai, India, and was followed by a workshop in October 2007 in Freiburg, Germany. The aim was to enable and improve planning and decision-making between different stakeholders, representatives of planning authorities, administrative managers, consumer and civil action groups, resident welfare organisations as well as affected community members. Especially the workshop in India provoked a high interest of the media and the public (Oppili, 2007). The visualisation of research results helped enormously to extend awareness regarding local problems, especially among politicians and city planners. It enabled policy makers to better learn:

(i) about the different dimensions of flooding in the last 10 years;

(ii) what it means to be affected by floods;

(iii) which coping as well as adaptation strategies are applied; and

(iv) what factors the local population perceives as the drivers of flooding.

Moreover, the interactive mental maps supported the efforts already undertaken by nature conservation and human rights organisations to influence political decisions.

Generally, better accessibility to reliable data is crucial for the improvement of planning all over India and elsewhere. In order to properly plan, manage and monitor programmes, it is vital that up-to-date information is available to actors at all levels (Few et al., 2004). Our planning tool is publicly available and can serve as an example for future projects (http://www.geographie.uni-freiburg.de/chennai/cd/).

\section{The potential of mental map visualisation}

The interactive mental map tool allowed for merging geospatial and socio-economic data. This interactive and interdisciplinary approach is a new way of transferring and communicating socio-economic data such as local perceptions, coping and adaptation strategies. The interactive way of communicating findings between different stakeholders initiates learning processes, which bear the potential to identify key areas of interventions more efficient- 


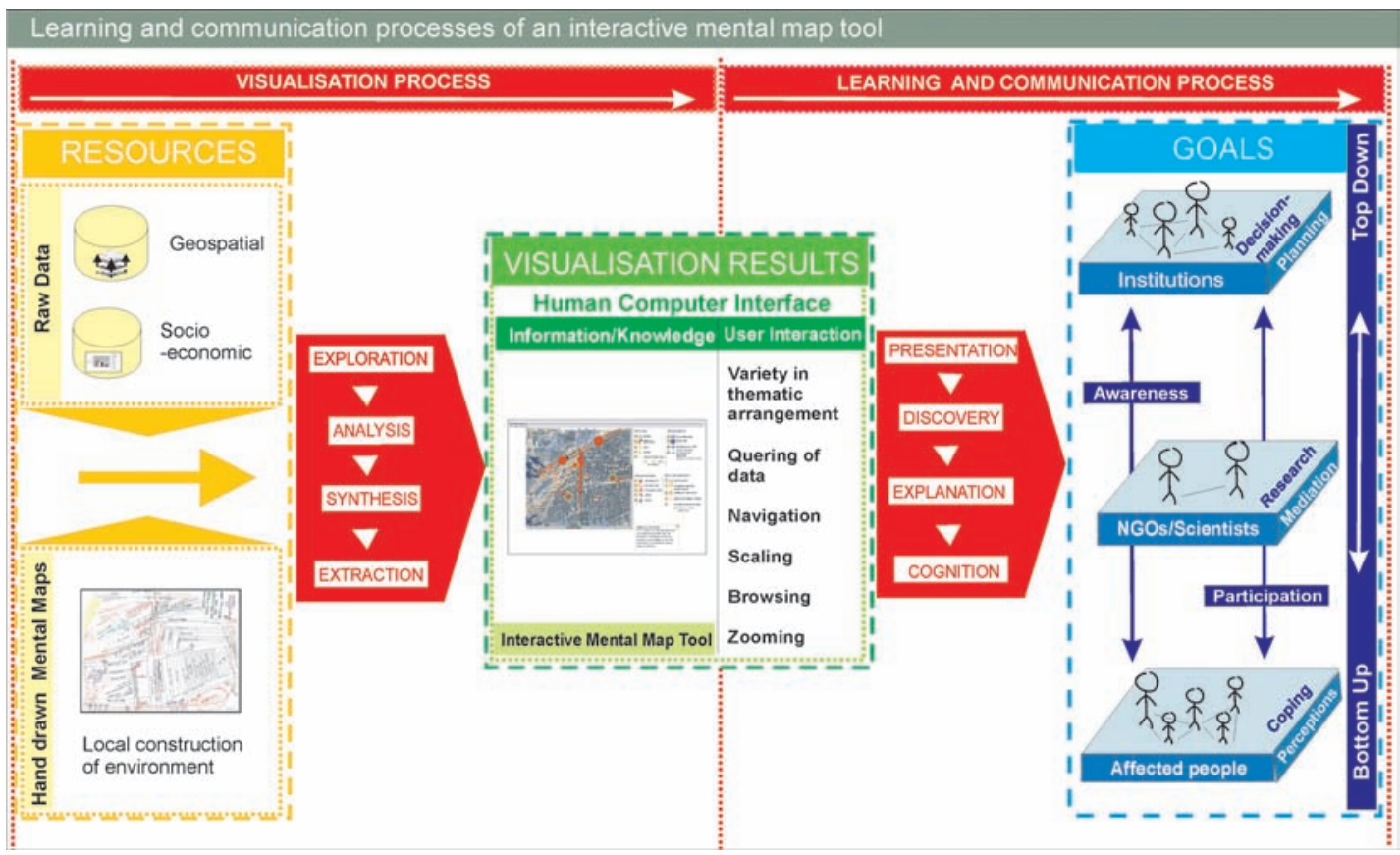

Fig. 6. Learning and communication process of an interactive mental map tool.

ly than just reading documents (Siebert, 2005). Cartographic communication stimulates the creation of spatial knowledge (Abbot et al., 1998; Rambaldi et al., 2004; Dransch, 1997, 2006). Browsing, navigating and zooming are elements of animations, which help to interactively understand a spatial phenomenon and to enhance knowledge. Trends and interrelationships can be revealed that might be overlooked otherwise or not appropriately acknowledged when presented in reports. However, learning is not a fully personal cognitive process. Knowledge can partly be passively received, but is mainly actively built up by interaction between actors. Knowledge generation therefore is a continuous process of construction. Communication is the link between individual cognition and social interaction. All knowledge derives from, and is maintained through interaction, communication and cooperation (Berger and Luckmann, 1966). Social constructivism argues that the most optimal learning environment is one where a dynamic interaction between different actors provides an opportunity to create meaning due to the interaction with others and the world. Figure 6 illustrates the various stages of the learning and communication process described above, which was initiated by the interactive mental map tool.

In our approach, we deliberately decided not to develop an expert-based tool, but rather to aim at providing an intuitively usable tool. Moreover, we chose software that may be installed on almost every system as browser plug-in, and used as standalone solution. This approach favoured software that could be easily downloaded. Furthermore, we aimed at a tool that can be used offline. Keeping these notions in mind, we chose a mental map approach that did not refer to already existing georeferenced maps which is common in PGIS. Thereby we wanted to visualise locally constructed positive or negative connotations of space, important landmarks or the perceived size of the covered geographical areas without providing a given spatial structure. However, we acknowledge that it is costand time saving to embed mental map activities in existing geo-referenced maps. Costs can be also reduced by working with Google Earth maps 
instead of satellite images. Although it is important to mention that Google Earth imagery is lacking any kind of meta data information and therefore is criticized as being non-scientific.

During mental map visualisation several challenges for developers as well as users of the tool need to be considered. Regarding the developers, adequate human as well as financial resources are of importance. Software acquisition and capacity building courses for untrained team members are one of the main challenges that might be faced by partners from the North, but perhaps even more so from the South. Personnel skilled in Flash application and GIS is often not easy to find. Moreover, the ability to access data, the negotiation process of merging interdisciplinary data within the team, the development of appropriate data visualisation as well as the duration of programming time are factors that contribute to a successful implementation. Last but not least, the user's willingness to use the tool is a prerequisite that should not be overlooked.

Despite these challenges, the presented tool is versatile and can be easily applied in other fields of research, which aim at initiating mutual learning processes between different actors. In international health research, interactive mental maps can temporally and spatially illustrate the combination of satellite images and local constructions of key themes such as collection and storage of water, waste disposal, availability and accessibility to existing health care services, disease outbreaks, breeding sites of disease vectors, location of appropriate refuge sites, availability of drinking water, location of public toilet sites, blocked sewage, as well as environmental hazards (Few, 2004; WHO, 2008).

We conclude that the transformation of mental maps in an interactive geospatial planning tool moves beyond classical geospatial approaches (i) by taking multifaceted local constructions into consideration, and (ii) by initiating multilevel learning and communication processes. We look forward to see other researcher taking up the challenge and improve and further develop our approach.

\section{Acknowledgements}

We thank the participants of the three study areas in Chennai. Additionally we thank the team of Care Earth for supporting us greatly during the data collection in Chennai. The underlying research was funded by the German Federal Ministry for Economic Cooperation and Development (BMZ) and commissioned by the Deutsche Gesellschaft für Technische Zusammenarbeit (GTZ) GmbH - Advisory Project "Disaster Risk Management in Development Cooperation" on behalf of the BMZ.

\section{References}

Abbot J, Chambers R, Dunn C, Harris T, de Merode E, Porter G, Townsend J, Weiner D, 1998. Participatory GIS: opportunity or oxymoron? PLA Notes 33, 27-34.

Barndt M, 1998. Public participation GIS-Barriers to implementation. Cartogr Geogr Inf Sys 25, 65-66.

Berger P, Luckmann T, 1966. The social construction of reality. A treatise in the sociology of knowledge. Anchor Books, New York, USA, 219 pp.

Bohle HG, 2001. Vulnerability and criticality. Perspectives from social geography. IHPD-Update 2, 1-5.

Chambers R, 1997. Whose reality counts? Putting the first last. Intermediate Technology Publications, London, UK, 317 pp.

Downs R, Stea D, 1982. Kognitive karten: die welt in unseren köpfen. Harper and Row, New York, USA, 392 pp.

Dransch D, 1997. Computer-animation in der Kartographie. Theorie und Praxis. Springer Verlag, Heidelberg, Germany, 145 pp.

Dransch D, 2006. Designing suitable cartographic multimedia presentations. In: Multimedia Cartography. B Cartwright, G Gartner, M Peterson (eds). Springer Verlag, Heidelberg, Germany, 75-87.

Dunn C, 2007. Participatory GIS - a people's GIS? Progr Hum Geog 31, 616-637.

Few R, Ahern M, Matthies F, Kovats S, 2004. Floods, health and climate change: a strategic review. Norwich Tyndall Centre for Climate Change Research, 129 pp.

Gesellschaft für Technische Zusammenarbeit (GTZ), 2004. Guidelines. Risk analysis - a basis for disaster management. GTZ, Eschborn, Germany, 31 pp. 
Glaser R, Lechner M, Bohle HG, Sauerborn R, Louis V, Sakdapolrak P, 2006. Wasserkrisen in der megacity Chennai in Südindien. In: Geographie. Physische Geographie und Humangeographie. H Gebhardt, R Glaser, U Radtke, P Reuber (eds). Spektrum, Heidelberg, Germany, 1009-1014. Harris T, Weiner D, 1998. Empowerment, marginalization, and "community-integrated" GIS. Cartogr Geogr Inf Sys 25, 67-76.

Lynch K, 1960. The image of the city. MIT Press, Cambridge, MA, USA, 202 pp.

MacEachren A, 2000. Cartography and GIS: facilitating collaboration. Progr Hum Geog 24, 445-456.

Mukherjee N, 1993. Participatory rural appraisal - methodology and applications. Concept Publishing Company, New Delhi, India, 433 pp.

Nestle M, Sakdapolrak P, Bohle HP, Glaser R, Louis V, Mistelbacher J, Sauerborn R, Gans P, Lechner M, 2005. Chennai. Umweltkrise und Gesundheitsrisiken in einer indischen Megacity. In: Planet Erde. R Glaser, K Kremb (eds). WBG, Darmstadt, Germany, pp. 209-214.

Oppili R, 2007. Pallikaranai vulnerable to devastating floods: study. Available: http://www.thehindu.com/2007/08/25/ stories /2007082561150500.htm (accessed: 26 April 2008).

Rambaldi G, McCall M, Weiner D, Mbile P, Kyem P, 2004. Participatory GIS...?, Available: http://www.iapad.org/participatory_gis.htm (Accessed: 15 March 2007).
Siebert H, 2005. Pädagogischer Konstruktivismus. Beltz Verlag, Weinheim/Basel, 150 pp.

Stallings R, 1995. Promoting risk: constructing the earthquake threat. Hawthorne/New York, Aldine de Gruyter, 248 pp.

Tomaszewski BM, Weaver C, Robinson AC, Stryker M, MacEachern AM, 2007. Geovisual analytics and crisis management. In: Proceedings of the 4th International ISCRAM Conference. B Van de Walle, P Burghardt, C Nieuwenhuis (eds). Delft, The Netherlands, 173-179.

Treibel A, 2000. Einführung in soziologische Theorien der Gegenwart, Opladen, Leske + Budrich, 275 pp.

Turner BL, Kasperson RG, Matson PA, McCarthy JJ, Corell RW, Christensen L, Eckley N, Kasperson J, Luers A, Martello ML, Polsky C, Pulsipher A, Schiller A, 2003. A framework for vulnerability analysis in sustainability science. Proceedings of the National Academy of Sciences 100, 8074-8079.

Vajjhala SP, 2006. “Ground Truthing” policy: using participatory map-making to connect citizens and decision makers. Resources for the Future 162, 14-18.

WHO, 2008. Public Health mapping and GIS. Available: http://www.who.int/health_mapping/en/ (Accessed: 15 March 2008).

Wright S, Nelson N, 1994. Power and participatory development: theory and practice. Intermediate Technology Publications, London, UK, 208 pp. 